\title{
CONSTITUCIONALIZACIÓN DEL DERECHO COMERCIAL DESDE LA DOGMÁTICA DE LOS MÁRGENES DE ACCIÓN
}

\author{
JUAN JACOBO CALDERÓN VILLEGAS
}

This article examines how the relationships between constitutional law and commercial law should be established. The process of constitutional inclusion of law is analyzed from the point of view of trade law, using for this purpose Robert Alexy's margins of action theory. Thereafter, the risk limitation principle for investors in stock companies is analyzed, as well as the constitutional inclusion of issues related with this principle, using sentences from the Constitutional Court.

Las sociedades que quisieran preservar su carácter pluralista deberían afirmar valores entre los que el equilibrio deba alcanzarse mediante la ponderación con otros valores del mismo tipo, sin la participación del médium homologador y desnaturalizador del dinero.

Gustavo Zagrebelsky, El derecho dúctil

\section{Introducción}

La afirmación de que el texto constitucional ha de ser tenido como fundamento y fuente de interpretación de la totalidad del ordenamiento jurídico ha generado el nacimiento y la configuración de interesantes y complejos problemas. Ellos se formulan desde las dificultades relativas a estos tres niveles:

1. El de la delimitación del alcance de los diversos campos en que se desenvuelve el conocimiento jurídico en relación con el derecho constitucional.

2. El de la definición de los sistemas interpretativos que deben desplegarse cuando tal delimitación no es posible o, en todo caso, no resulta clara. 
3. Como consecuencia de lo anterior, el de la determinación dogmática e institucional de los alcances de la competencia que corresponden a la jurisdicción ordinaria y a la jurisdicción constitucional para abordar las cuestiones jurídicas que se ubican, por decir así, en una especie de zona de penumbra competencial vinculada a una indefinición prima facie de las fuentes de derecho relevantes.

La aceptación de la fuerza expansiva de la Constitución y, en especial, del sistema de los derechos fundamentales, obliga a que tales niveles de dificultades sean examinados desde una perspectiva que contribuya a equilibrar la exigencia de constitucionalización máxima del derecho y la demanda de conservación de autonomía interpretativa y epistemológica de los diversos campos del saber jurídico.

El derecho comercial y la actividad mercantil no resultan ajenos a las cuestiones que plantea la constitucionalización del ordenamiento jurídico. Esa exigencia es de por sí muy compleja: no solo es jurídica sino también política; se deriva de la definición de la Constitución como norma de normas (artículo 4), del reconocimiento de la primacía de los derechos inalienables de la persona (artículo 5), de la consagración del poder vinculante de la Constitución respecto de todos los poderes públicos y de los particulares (artículo 6), y de la institucionalización de sistemas judiciales para garantizar la defensa e integridad del texto constitucional (artículos 86 y 241). Se impone, entonces, la necesidad de analizar la manera en que deben definirse las relaciones entre el derecho constitucional y el derecho comercial. La idea de una constitucionalización adecuada del derecho comercial se opone tanto a la pretensión de que la Constitución resuelve definitivamente la totalidad de las cuestiones jurídicas que caen en el objeto propio de este derecho (sobreconstitucionalización), como a la consideración según la cual la Constitución no se encuentra en capacidad de resolver, definitivamente, ningún asunto de esta naturaleza (infraconstitucionalización) ${ }^{1}$.

Para contribuir con el trabajo de constitucionalización, abordaré algunas cuestiones fundamentales en relación con el derecho mercantil, con la intención de definir un conjunto de líneas básicas que permitan el desarrollo de una investigación futura. Expongo el orden que seguiré. En primer lugar, expondré la naturaleza del problema central que se plantea con la exigencia de constitucionalización. En segundo lugar, me detendré en la consideración de la naturaleza del principio de

\footnotetext{
${ }^{1}$ Sobre una constitucionalización adecuada del ordenamiento jurídico puede consultarse,

Robert Alexy, Tres escritos sobre los derechos fundamentales y la teoría de los principios, Universidad Externado de Colombia, Bogotá, 2003, Pág. 50 y ss.
} 
limitación del riesgo de los accionistas en las sociedades anónimas y expondré las restricciones a las que se encuentra sometido. A continuación, en la tercera parte del artículo, iniciaré el análisis de la constitucionalización de cuestiones vinculadas con dicho principio de limitación, para lo cual me basaré en sentencias proferidas por la Corte Constitucional. La tarea que me propongo es describir las tesis jurídicas básicas contenidas en dichas sentencias y exponer las críticas que frente a tales tesis ha formulado un sector de la doctrina colombiana. En cuarto lugar seguiré los lineamientos del profesor Robert Alexy para explicar cómo es posible llevar a cabo una constitucionalización correcta del ordenamiento jurídico a partir de la denominada dogmática de los márgenes de acción. Aunque a partir de dicha dogmática no resulta posible lograr un total consenso sobre el problema jurídico resuelto en las sentencias escogidas para el presente análisis, en la quinta sección explicaré cómo a partir de algunos de sus conceptos básicos constitutivos sí es viable: (i) la exposición clara de los alcances de la controversia, (ii) la fundamentación de la manera como debe explicarse la eficacia regulativa del derecho comercial y del derecho constitucional y (iii) conferir un nivel mayor de objetividad a los debates que se plantean alrededor de la constitucionalización del derecho. En sexto lugar y a manera de conclusión se presentarán algunas tesis que permitirían revitalizar correctamente la manera como deben plantearse las relaciones entre el Derecho Comercial y el Derecho Constitucional.

\section{La exigencia de constitucionalización del ordenamiento jurídico: funda- mento y consecuencias}

En la introducción de este trabajo han sido trazados los fundamentos básicos que justifican normativamente la constitucionalización del derecho colombiano ${ }^{2}$. De tal justificación normativa se desprende la necesidad de describir la manera en que ello debe ocurrir. En efecto, la configuración de un sistema jurídico que garantice la

\footnotetext{
${ }^{2}$ En relación con una visión conceptual del proceso de constitucionalización del ordenamiento jurídico, puede consultarse Ricardo Guastini, La Constitucionalización del Ordenamiento Jurídico: El caso italiano, en Neoconstitucionalismo, Ed,. Trotta, 2003, Pág. 49 y ss. El Profesor R. Alexy, refiriéndose al caso alemán ha expuesto que el problema de la expansión de los contenidos constitucionales en el derecho alemán se produjo a partir del conocido caso Luth en el que se desarrollaron las tres ideas siguientes: (a) "El catalogo de los derechos fundamentales no sólo garantiza derechos de defensa sino que también enuncia todo un sistema de normas";

(b) "Si los derechos fundamentales vinculan a los tres poderes públicos y son principios, entonces también vinculan a los tres poderes públicos como principios"; (c) "los valores o principios tienden a entrar en colisión. Como consecuencia, el enunciado fundamental para el quehacer jurídico cotidiano es el siguiente: "por lo tanto, es indispensable llevar a cabo una ponderación de bienes"”, Robert Alexy, Tres escritos... Cit, p. 43 y ss. Sobre la constitucionalización en Francia puede consultarse, Louis Favoreu, Legalidad y constitucionalidad. La constitucionalización del derecho, Universidad Externado de Colombia, Bogotá, 2000.
} 
realización efectiva de las cláusulas constitucionales dado su carácter normativo y que establezca instancias institucionales específicas para garantizar tal carácter, impide omitir el análisis de la manera en que dichas cláusulas deben proyectar su eficacia en cada uno de los ámbitos del derecho. Adicionalmente, el hecho de que la Constitución hubiese previsto no sólo el marco general mencionado sino también que hubiera expresado un sistema de predilección orientado a la eficacia de los derechos constitucionales fundamentales ${ }^{3}$, permite concluir que la exigencia de sujeción de la totalidad del ordenamiento jurídico a las normas iusfundamentales ${ }^{4}$ adquiere un nivel de intensidad superior. Esto exige que el análisis en relación con la eficacia de tales normas se desarrolle con mayor detenimiento y cuidado.

Los problemas relacionados con la constitucionalización abarcan cuestiones vinculadas con la producción, la interpretación y la aplicación del derecho. En este sentido, la determinación de la manera en que debe operar la constitucionalización requiere ocuparse de aspectos que aluden (i) al contenido posible de las normas que pueden expedir los órganos autorizados para ello (contenido sustancial posible), (ii) a la forma en que tal expedición puede llevarse a cabo (procedimiento formal posible), (iii) al tipo de interpretaciones admisibles de las normas existentes (contenidos interpretativos posibles) y (iv) a la determinación de los resultados concretos según las interpretaciones adoptadas (efectos interpretativos posibles).

Estos aspectos conducen, a su vez, al planteamiento de complejos problemas relacionados con el alcance de las competencias atribuidas a las autoridades en la producción del derecho -en sentido amplio ${ }^{5}$-. Así, por ejemplo, se discute cuáles son los límites a los que debe ajustar su actuación la Corte Constitucional cuando 52 examina la constitucionalidad de una ley expedida por el Congreso, y cuáles son los parámetros que deben orientar a los jueces constitucionales cuando se propone una vía de hecho judicial por cualquiera de los defectos admitidos por la jurisprudencia constitucional ${ }^{6}$.

\footnotetext{
${ }^{3}$ Esto a través de la consagración de un catalogo extenso de los derechos fundamentales y de mecanismos judiciales para lograr su protección

${ }^{4}$ Con la expresión iusfundamental se pretende hacer referencia a derecho fundamental. Esta expresión ha sido acogida no sólo en la literatura jurídica en materia de derechos fundamentales sino también en la jurisprudencia constitucional colombiana relacionada con la materia.

${ }^{5}$ La producción a la que me refiero no se relaciona, exclusivamente, con la actividad legislativa. Ella abarca, al menos, los sistemas de producción legislativa, administrativa y judicial de derecho. ${ }^{6}$ En principio podría aludirse a cuatro defectos: defecto sustantivo, defecto fáctico, defecto orgánico y defecto procedimental.
} 
Si se exploran con mayor detenimiento los efectos de la pretensión de constitucionalizar el derecho privado pueden ser constatados aprietos adicionales. En todo caso, tales aprietos se incrementan debido al vínculo existente entre los derechos fundamentales y el axioma de la autonomía de la voluntad que gobierna el sistema de derecho privado y, en especial, el derecho comercial. A este par de cuestiones me referiré a continuación.

El diseño del derecho privado se fundamenta en el principio de la autonomía de la voluntad, el cual garantiza que los particulares puedan orientar su conducta privada y regular sus relaciones de negocios con total libertad. Ello tiene como consecuencia que la posibilidad del Estado para intervenir en tal ámbito ostentaría un carácter excepcional dado que sólo resultaría viable tal intervención cuando existiese una razón política o jurídica poderosa. Tal tipo de razones se configurarían, por ejemplo, cuando (i) se pactaran cláusulas contractuales contrarias al orden público o a una previsión legal expresa ${ }^{7}$, (ii) se pretendiera abusar de una especial posición (dominante) en el mercado ${ }^{8}$, (iii) se intentara imponer cláusulas que por su naturaleza fuesen abusivas ${ }^{9}$, (iv) se articularan mecanismos de engaño, confusión o abuso del consumidor ${ }^{10}$ o (v) se emplearan mecanismos de organización societaria que pudieran tener como consecuencia la afectación de los intereses de los acreedores ${ }^{11}$.

\footnotetext{
${ }^{7}$ Podrían considerarse cláusulas de este tipo las siguientes: (a) Aquella en virtud de la cual el Agente Comercial, de antemano, renunciara a la prestación mercantil a que tiene derecho según lo dispuesto en el primer inciso del artículo 1324 del Código de Comercio o (b) aquella dirigida a establecer en un contrato de fiducia mercantil la posibilidad de conceder el beneficio a diversas personas sucesivamente (artículo 1230 C. de Co.)

${ }^{8}$ Por ejemplo, según lo dispuesto por el numeral 1 del artículo 50 del decreto 2153 de 1992 la disminución de precios por debajo de los costos cuando ello tenga por objeto eliminar uno o varios competidores o prevenir la extensión o expansión de estos. Así mismo la Corte Constitucional en sentencia T-1118 de 2002 (M.P. Manuel José Cepeda Espinosa) ha reconocido la imposibilidad de aducir razones fundadas en la libertad contractual y de empresa por parte de una compañía aseguradora a fin de negarse a cotizar el valor de un seguro a un grupo de discapacitados.

${ }^{9}$ Es por ello que la sala Civil de la Corte Suprema de Justicia ha sostenido que la obligación de presentar una sentencia judicial que declare la responsabilidad de un tercero a fin de proceder a la reclamación ante la aseguradora es claramente abusiva.

${ }^{10}$ En este sentido el artículo 17 del decreto 3466 ha establecido que en los casos de bienes o servicios que por su naturaleza o componentes, sean nocivos para la salud, deberá indicarse claramente y en caracteres perfectamente legibles (i) su carácter nocivo, (ii) las condiciones o indicaciones necesarias para su correcta utilización y (iii) las contraindicaciones respectivas.

${ }^{11}$ Por ejemplo la consagración legal (artículo 262 del C. de Co. Modificado por el artículo 32 de la ley 222 de 1995) de la prohibición de imbricación de conformidad con la cual las sociedades subordinadas no podrán tener a ningún título, partes de interés, cuotas o acciones en las sociedades que las dirigen o controlan.
} 
Es claro, por lo tanto, que la intervención en la esfera negocial de los particulares se encuentra ligada, en un número importante de casos, a que el tipo de intervención y su ejecución estén contempladas previa, específica y claramente en algún texto normativo. Esta estructura adquiere una relevancia significativa en el campo del derecho comercial si se tiene en cuenta que las actividades mercantiles necesitan contar con niveles de seguridad jurídica tolerables y medidas de protección del capital estables, pues suponen una inversión importante, un interés de lucro permanente y se desenvuelven en un mundo cada vez más relacionado económicamente. Estas garantías podrían encontrarse en la permanencia, claridad y consistencia de las reglas que autorizan la intervención correspondiente en la autonomía de la voluntad ${ }^{12}$.

De la anterior afirmación se derivan con claridad los problemas que la expansión de los contenidos iusfundamentales puede provocar en la interpretación y aplicación del derecho comercial. En efecto, si se acepta, como creo debe aceptarse, (1) que además del tipo de intervenciones mencionadas más arriba, los derechos fundamentales constituyen razones de primer orden para justificar otro tipo de interferencias en el principio de la autonomía de la voluntad propia del derecho mercantil y (2) que las normas de derecho fundamental poseen una estructura de principios ${ }^{13}$, lo cual supone que tales normas son mandatos que ordenan que algo sea realizado en la mayor medida posible dependiendo de las posibilidades jurídicas y fácticas ${ }^{14}$, debe concluirse (3) que la constitucionalización del derecho comercial se expone a nutrirse de problemas adicionales derivados de la aplicación de categorías tradicionalmente constitucionales y, de esta manera, a someter al mandato de ponderación (principio de proporcionalidad en sentido estricto) las soluciones elaboradas dentro del derecho mercantil.

No es del caso, en este lugar, referirnos al tipo de exigencias argumentativas que se derivan de cada una de las máximas que componen el principio de propor-

\footnotetext{
${ }^{12}$ Sobre el desarrollo de algunas de estas ideas puede revisarse Jorge Pinzón Sánchez, El Código de Comercio treinta años después de su expedición: algunas reflexiones acerca del sentido actual de una codificación en materia mercantil, Revista de Derecho Privado No. 31, 2004.

${ }^{13}$ Sobre el entendimiento de los derechos fundamentales como principios puede consultarse, Robert Alexy, El concepto y la validez del derecho, Sistema Jurídico y Razón Práctica, Editorial Gedisa, Barcelona 2004, pág. 159 y ss.

${ }^{14}$ Robert Alexy, Teoría de los derechos fundamentales, Centro de Estudios Constitucionales, Madrid, 1993, pág. 86. En este sentido, a diferencia de las reglas que definen de una vez lo fáctica y jurídicamente posible, los principios ostentan un carácter de indeterminación tal que no permiten llegar a conclusiones definitivas antes de desarrollar un proceso metodológico complejo que debe desenvolverse, necesariamente, a través de las máximas de adecuación, necesidad y estricta proporcionalidad.
} 
cionalidad en sentido amplio ${ }^{15}$. Tan sólo resulta necesario señalar que la máxima de proporcionalidad en sentido estricto impone la obligación de que, ante un conflicto de intereses de relevancia constitucional, se desarrolle un proceso de ponderación a fin de determinar si la restricción de un derecho fundamental vinculado al derecho mercantil se encuentra justificada por la importancia de las razones que se aducen para tal efecto.

Los problemas del anterior razonamiento son evidentes. Si se acogiera la idea según la cual cada asunto relevante para el derecho mercantil debe ser sometido a un examen de proporcionalidad en sentido estricto, ello (i) implicaría una notable indeterminación previa de las normas aplicables a cada cuestión, afectando así las exigencias de seguridad jurídica que reclaman las relaciones mercantiles, (ii) determinaría la eliminación de competencia legislativa en esta materia y (iii) supondría que la totalidad de los problemas relevantes para el derecho mercantil serían, en realidad, problemas constitucionales cuya definición podría encomendarse a la Corte Constitucional.

Ello desde luego no es deseable si se tiene en cuenta que ninguno de tales efectos contribuye a la racionalidad del sistema jurídico. Sin embargo una infraconstitucionalización del derecho mercantil tampoco resulta admisible. En consecuencia, es necesario buscar un nivel adecuado de constitucionalización. La dogmática de los márgenes de acción se dirige, precisamente, a fijar límites claros, controlables y correctos en relación con el alcance de la expansión iusfundamental. En palabras de R. Alexy "una constitucionalización adecuada sólo puede construirse por el camino pedregoso y arduo de la dogmática de los márgenes de acción"16.

\section{Análisis constitucional del principio de limitación de la responsabilidad} de los accionistas en las sociedades anónimas.

\subsection{El principio de limitación del riesgo patrimonial: Una aproximación a su alcance y restricciones.}

Una de las principales justificaciones para la existencia de las diversas formas de personificación jurídica consiste en que este mecanismo permite diferenciar las actividades de la persona jurídica de las actividades de los individuos que, al

\footnotetext{
${ }^{15}$ Sobre el especial vínculo entre la máxima de proporcionalidad en sentido amplio y la teoría de los principios, puede consultarse Robert Alexy, Teoría de... Cit, p. 112 y ss. De igual manera puede consultarse, Juan Jacobo Calderón Villegas, Una Aproximación al Influjo Dogmático de Robert Alexy en la Jurisprudencia Constitucional de los Derechos Fundamentales, Universidad de Caldas, Págs. 223 y ss, 2004

${ }^{16}$ Robert Alexy, Tres escritos... Cit, p. 53.
} 
ejercer su derecho de asociación, establecen y organizan actividades comerciales $^{17}$. Esta diferenciación busca diluir los riesgos en que pueden incurrir las personas, individualmente consideradas, al adoptar conductas mercantiles ${ }^{18}$.

La limitación del riesgo a través de la constitución de personas jurídicas no se manifiesta de la misma manera y con idéntica intensidad en todos los casos. En efecto, el estudio del régimen societario contenido en el Código de Comercio permite determinar que el nivel de tal limitación es diverso según se trate de sociedades colectivas o de sociedades anónimas. En el primer caso, los socios responden solidaria e ilimitadamente -aunque de manera subsidiaria - por el pasivo externo de la sociedad. En el caso de las sociedades anónimas, por el contrario, los accionistas únicamente son responsables, en principio y ante la sociedad, por el pago de sus respectivos aportes ${ }^{19}$.

El nivel de vigor con que opera tal principio se relaciona igualmente con cuestiones operativas y administrativas de la sociedad. Así por ejemplo, como corolario del leve influjo de tal principio en las sociedades colectivas, la administración corresponde a todos los socios ${ }^{20}$. Cosa diferente

\footnotetext{
${ }^{17}$ Ello no quiere decir, en modo alguno, que se desconozca la existencia de personas jurídicas cuyas finalidades son ajenas a toda actividad comercial. Este aserto es claramente reconocido por la Corte Constitucional cuando, al referirse a la finalidad del Derecho de Asociación sostiene lo siguiente: " $\mathrm{La}$ finalidad de este derecho constitucional se plasma entonces en la creación de entes jurídicos distintos de las personas naturales con capacidad para ejercer derechos y contraer obligaciones, en aras de lograr la satisfacción de un interés u objetivo común, no siempre ligado a la obtención de lucro", Corte Constitucional, Sentencia C-865 de 2004, M.P. Rodrigo Escobar Gil.

${ }^{18}$ El profesor Guillermo Julio Borda, expone en los siguientes términos la importancia del concepto de persona jurídica: "Hoy en día es impensable que la concreción de las monumentales obras que vemos realizar, las innovaciones tecnológicas del proceso productivo, los trabajos de investigación, etc., que la sociedad moderna exige como algo imprescindible, a diario y con una necesidad impostergable, puedan ser emprendidos y llevados a cabo por una sola persona; son el fruto del trabajo colectivo, y este trabajo colectivo se efectúa bajo diversas formas asociativas tales como las sociedades anónimas, de responsabilidad limitada, cooperativas, fundaciones, asociaciones civiles ,entre otras", El abuso de la persona jurídica en el contrato de sociedad, en Contratación Contemporánea 2, Ed. Temis-Palestra 2001, Pág. 265.

${ }^{19}$ Esta conclusión se sigue de la lectura conjunta de los artículos 252 y 373 del Código de Comercio.

${ }^{20}$ La Corte Constitucional de Colombia ligando esta cuestión al alcance de la libertad de configuración del legislador indicó: "Destáquese como en ejercicio de su potestad de configuración normativa, el legislador asimiló el interés personal o familiar de las sociedades intuitus personarum a la competencia para administrar la empresa social, suponiendo a todos los socios como administradores y adjudicándoles una responsabilidad solidaria e ilimitada por el manejo directo e inmediato de las operaciones sociales del ente moral (C. Co., arts. 294, 310, 323 y 326). En esta hipótesis, ante la existencia de una justa causa valorada por el legislador, se atenuó el principio de limitación de riesgo como expresión del patrimonio propio de la sociedad (atributo de la personalidad), extendiendo a los asociados la responsabilidad por las acreencias de la persona jurídica", Corte Constitucional, Sentencia C-865 de 2004, M.P. Rodrigo Escobar Gil.
} 
ocurre en las sociedades anónimas, ya que en su administración no participan la totalidad de los accionistas ${ }^{21}$.

Resulta claro entonces que una de las motivaciones centrales de las personas que deciden crear una sociedad anónima consiste en proteger su integridad patrimonial de los factores que pueden alterar el desarrollo de la actividad mercantil ${ }^{22}$.

Tal protección es consecuencia de la incomunicación que el ente societario establece entre el patrimonio de los accionistas y el patrimonio de la sociedad. El profesor Reyes Villamizar ha expuesto sobre el particular: "Esta separación patrimonial entraña dos efectos jurídicos muy conocidos: en primer lugar, que los acreedores de los socios o accionistas no pueden ir contra los bienes de la sociedad para obtener la satisfacción de sus créditos (a lo sumo, podrán perseguir las participaciones de capital que estos tengan en aquella); en segundo término, que los acreedores de la compañía no pueden ir en contra de los bienes de los socios o accionistas para cubrir con su producto acreencias de la compañía"23

De acuerdo con lo anterior, se puede afirmar que la sociedad anónima promueve las actividades de inversión gracias a que la limitación del riesgo que la caracteriza motiva a los accionistas a entregar sumas de dinero considerables para constituir el fondo social ${ }^{24}$. Es por ello que puede considerarse la existencia del mencionado tipo societario como una condición fundamental para el desarrollo de la inversión extranjera.

\footnotetext{
${ }^{21}$ Sería admisible, igualmente, efectuar un razonamiento contrario. En efecto, podría afirmarse que la razón para que en la sociedad colectiva los socios respondan y solidaria e limitadamente obedece al hecho de que a todos ellos corresponde la administración. En el caso de las sociedades anónimas el argumento consistiría en afirmar que, dado que la administración en tal tipo societario no se encuentra radicada en la totalidad de los accionistas, se encuentra justificada la limitación de la responsabilidad de los mismos.

${ }^{22}$ El Profesor Ignacio Sanín Bernal se ha referido con claridad a esta cuestión. Ha indicado lo siguiente: "La barrera de la limitación de la responsabilidad que impide que las acreencias de la sociedad penetren y afecten el patrimonio de los asociados capitalistas (Inversores al capital social y aportantes), que es la salvaguarda de la indemnidad de los asociados, que limita el riesgo a que se pierda solo el aporte, es la razón de ser y el motivo y la causa de la celebración de un determinado tipo de sociedad", Un Nuevo Derecho Societario: El propuesto desde el Estatuto Tributario, Ed. Temis, 2001, Págs. 36 y 37. ${ }^{23}$ Francisco reyes Villamizar, Derecho Societario I, Ed. Temis, 2002, Pág. 177.

${ }^{24}$ El profesor Gabino Pinzón señala sobre el particular: "Porque el proceso de formación de la sociedad anónima no se presenta simplemente como el desarrollo de una tendencia a la limitación de la responsabilidad de los asociados, sino como un esfuerzo por conseguir la reunión de grandes capitales. La limitación de la responsabilidad no puede ser concebida como un ideal en la vida de los negocios, sino como una medida de tolerancia, o más exactamente, como un modo de estimular la inversión o de facilitar la vinculación de toda clase de inversionistas"., Sociedades Comerciales VOL. II, Ed Temis, 1983, pág 155 y 156.
} 
Se ha hecho una especial referencia a la sociedad anónima dado que esta constituye el paradigma de modelo societario limitante de la responsabilidad de los accionistas. El análisis de esta modalidad societaria es la que puede sugerir un mayor nivel de resistencia frente a las hipótesis que autorizan levantar el velo corporativo al amparo de la denominada teoría del "disregard of legal entity"

La aceptación jurídica de la posibilidad de levantar el velo corporativo de una sociedad encuentra dificultades de diversa naturaleza. Entre ellas cabe destacar, de manera principal, la muy arraigada concepción de que el cumplimiento de los trámites legalmente exigidos para constituir una persona jurídica debe tener como consecuencia necesaria la aceptación permanente de que la misma es una entidad diferente de los socios y que esta es la razón que justifica su regulación como tal. Esta afirmación implica la imposibilidad de imputar responsabilidad a los asociados por las actividades formalmente desarrolladas por la sociedad.

Tal razonamiento supondría que la intromisión estatal en la sociedad para levantar el manto bajo el cual actúan los asociados sería una manifestación evidente de la crisis de la noción de persona jurídica. No obstante, Reyes Villamizar acepta la posibilidad de adoptar excepcionalmente medidas que habiliten tal intromisión (hipótesis de excepción) y establece, de forma ciertamente correcta, que una visión más optimista, con la cual nos identificamos, permite pensar que tales instrumentos de excepción, lejos de comprobar la crisis de la personalidad jurídica de la sociedad, demuestran su capacidad de adaptación a las circunstancias adversas que atentan contra su prevalencia en el régimen societario ${ }^{26}$.

En todo caso, al margen de las consecuencias que pueda traer para el concepto de persona jurídica la aplicación de la teoría del disregard of legal entity, es evidente que razones éticas y constitucionales justifican su procedencia bajo determinadas condiciones.

Las condiciones aludidas se activan cuando la persona jurídica "es utilizada abusivamente, apartándose de los fines lícitos, en perjuicio de terceros que se relacionan jurídicamente con la sociedad, sean tales relaciones contractuales o de cualquier otra clase"27.

\footnotetext{
${ }^{25}$ Para aproximarse al estudio del desarrollo de esta teoría en el derecho inglés, norteamericano, español, uruguayo y argentino puede consultarse Guillermo Julio Borda, Ob. Cit. Págs. 274 y ss.

${ }^{26}$ Ob. Cit. Pág. 181

${ }^{27}$ Zulema Zárate, Hilda, "Personalidad jurídica y su desestimación”, http://www.estig.ipbeja.pt/ $\sim$ ac_direito/Zarate.pdf
} 
En el ordenamiento jurídico colombiano existen eventos en los que se manifiesta la anterior teoría y que, en consecuencia, restringen el principio de limitación del riesgo de los accionistas. Así y a título de ejemplo, (i) el inciso cuarto del artículo 105 del Código de Comercio establece que los asociados y quienes actúen como administradores responderán ilimitada y solidariamente por el pasivo externo y por los perjuicios causados. De igual forma (ii) el parágrafo del artículo 148 de la ley 222 de 1995 establece que cuando una situación de concordato o de liquidación obligatoria haya sido producida por causa o con ocasión de las actuaciones que hay a realizado la sociedad matriz o controlante en virtud de la subordinación y en interés de ésta o de cualquiera de sus subordinadas y en contra del beneficio de la sociedad en concordato, la matriz o controlante responderá en forma subsidiaria por las obligaciones de aquella. Finalmente, (iii) el primer inciso del artículo 207 de la citada ley señala que cuando los bienes de la liquidación sean insuficientes para cubrir el total de los créditos reconocidos y se demuestre que los socios utilizaron la sociedad para defrandar a los acreedores, serán responsables del pago del faltante del pasivo externo, en proporción a los derechos que cada uno tenga en la sociedad.

Aunque los supuestos enunciados no agotan el espectro de situaciones cobijadas por la teoría que se viene comentando, es claro que de su lectura se extraen algunas de las claves que fundamentan su aplicación. En efecto, resulta claro que es viable proceder a desconocer la incomunicación patrimonial y descubrir a los asociados, antes jurídicamente ocultos, si (a) los motivos que inducen a celebrar el contrato de sociedad son ilícitos o si las prestaciones a que se obligan los asociados o la sociedad desconocen la ley o el orden público ${ }^{28}$; (b) si la situación de concordato o liquidación obligatoria en la que se encuentra la sociedad y que le impide cubrir sus obligaciones ha sido causada por la actividad de la sociedad controlante o matriz en su propio interés o de otras sociedades a ella vinculadas; (c) si la constitución de la sociedad, en liquidación, tuvo como finalidad defraudar o evadir la acción de los acreedores o ha sido empleada para ello, y carece de recursos para cubrir su pasivo externo.

Así las cosas, cuando la sociedad es empleada para fines diferentes a aquellos que sustentan su regulación en los ordenamientos jurídicos, tales como el desarrollo de actividades prohibidas o el desconocimiento de los derechos de los acreedores de los accionistas o de la sociedad misma, el Estado se encuentra habilitado para interferir en su acción ${ }^{29}$. Ello puede tener entre sus finalidades (a) la protección del traba-

\footnotetext{
${ }^{28}$ Inciso tercero del artículo 104 del Estatuto Mercantil.

${ }^{29}$ El Profesor Guillermo Julio Borda se ha ocupado de tal asunto indicando lo siguiente: "En el cambiante mundo de los negocios y sobre todo hoy, en este mundo globalizado que nos toca vivir, se ha utilizado la figura de la persona jurídica, y dentro de ella a la sociedad anónima, como una herramienta formidable para el cambio, la transformación y por sobre todo, para la concentración de capitales. Pero esta herramienta creada y pensada para hacer posible ese cambio y transformación, dio también lugar a un uso inescrupuloso, utilizando la persona jurídica en forma abusiva en detrimento de terceros, es decir, terminó siendo utilizada la figura de la persona jurídica para un fin contrario para el que fue concebida", Págs. 287 y 288.
} 
jo, (b) la garantía de la integridad patrimonial de terceros, (c) el amparo de la integridad del orden jurídico y (d) la salvaguarda de la buena fe.

Desde un punto de vista fundamentalmente doctrinal, el anterior análisis ha permitido constatar las ideas básicas relacionadas con el alcance del principio de limitación de la responsabilidad patrimonial y con las restricciones que cabe predicar de tal principio. A continuación se presentarán algunas de las consideraciones expuestas por la Corte Constitucional en la sentencia C-865 de 2004 que se relacionan con el fundamento y alcance constitucional del principio de limitación del riesgo en las sociedades anónimas.

\subsection{Fundamento constitucional del alcance y restricciones del principio de limitación del riesgo patrimonial en las sociedades anónimas}

En la sentencia C-865 de 2004 a la Corte Constitucional le correspondió evaluar si el legislador había incurrido en una omisión legislativa de carácter inconstitucional al no contemplar en el Código de Comercio, y en especial en el artículo 373 de dicho estatuto, que los accionistas de la sociedad anónima debían responder patrimonialmente por los pasivos laborales.

La Corte Constitucional estableció que el cargo de inconstitucionalidad formulado en contra del artículo 373 del Código de Comercio carecía de vocación de éxito. Para arribar a tal conclusión, la Corte desarrolló una argumentación compuesta, fundamentalmente, por seis( 6) niveles, tal y como se señala a continuación:

a. En el nivel inicial la Corte identifica las posiciones adscritas a la norma constitucional que consagra el derecho de asociación indicando que tal derecho garantiza no sólo (a) la decisión de asociarse con el objeto de dar lugar al nacimiento de una persona jurídica, sino también (b) la decisión de no hacerlo.

Así mismo, en el nivel que se comenta, la sentencia determina, en abstracto, las razones en las que se pueden sustentar las restricciones que se imponen al derecho de asociación. De esta manera, la Corte señala que tales restricciones pueden fundarse (i) en la prohibición constitucional de ejercitar abusivamente los derechos, (ii) en la exigencia de respetar los derechos ajenos y (iii) en la necesidad de salvaguardar la moral pública, la seguridad nacional, la seguridad jurídica y el orden público. 
b. Luego de hacer referencia a la naturaleza de las personas jurídicas y de las sociedades, deteniéndose en destacar los atributos que cabe atribuir a tal tipo de entes, la Corte pone de relieve la importancia de la estructuración del patrimonio de dichas organizaciones. Luego de reconocer la trascendencia de la separación patrimonial generada por la persona jurídica-sociedad, la sentencia advierte que es responsabilidad del legislador determinar la forma en que deben operar cada uno de los atributos de la personalidad en el desarrollo de la sociedad.

De esta manera la sentencia advierte, en el fundamento jurídico 17, que "De conformidad con lo previsto en el artículo 150 (nums. 2ํy 8) en armonía con lo dispuesto en el artículo 189 (num. 24) de la Constitución Política, le corresponde al legislador regular no sólo la denominación de las tipologías societarias (tales como, sociedades colectivas, en comandita, de responsabilidad limitada, anónima, mixta, etc.) sino también definir la preservación de sus atributos como personas jurídicas".

El dilatado campo de configuración ${ }^{30}$ que se le reconoce al legislador en esta materia permite, según se señaló, que éste determine la manera en que se articulan los diversos atributos de las sociedad y, en palabras de la Corte, en qué medida los atributos que definen su personalidad operan con mayor o menor intensidad.

c. Seguidamente la providencia destaca cómo el patrimonio, en tanto atributo de la personalidad, acentúa su fuerza con una potencia diferente según se trate de sociedades de capital o sociedades de personas. En efecto, en las primeras, la relevancia del patrimonio se revela con una potencia tal que se admite, prima facie, una separación patrimonial extrema. Es decir, el patrimonio de los accionistas, en principio, nunca podrá verse afectado como consecuencia de las actividades de la sociedad ${ }^{31}$.

Por el contrario, en el segundo tipo de sociedades, el patrimonio atenúa su fortaleza de forma tal que la incomunicación patrimonial se debilita y, por lo tanto, el patrimonio de los socios puede resultar comprometido con ocasión de la actividad de la sociedad ${ }^{32}$.

\footnotetext{
${ }^{30}$ Como se verá más adelante, expresiones tales como libertad de configuración pueden explicarse a la luz del concepto de margen de acción empleado por Alexy para definir los cauces a través de los cuales debe desarrollarse un proceso de constitucionalización adecuado.

${ }^{31} \mathrm{La}$ Corte Constitucional se refiere a este tipo de sociedades como sociedades de riesgo limitado.

${ }^{32}$ En la sentencia a la que se hace referencia se denomina a este tipo de sociedades como sociedades de riesgo ilimitado.
} 
La preferencia legislativa por una separación patrimonial considerable en el caso de las sociedades anónimas persigue, en opinión de la Corte, finalidades constitucionalmente admisibles, tales como permitir la circulación de riqueza como medio idóneo para lograr el desarrollo y el crecimiento económico del país.

d. En el cuarto nivel de su argumento, la Corte Constitucional adscribe al principio de limitación del riesgo de los accionistas de las sociedades anónimas un derecho del mismo contenido que tendría (i) como titulares o portadores del derecho a los accionistas y (ii) como destinatario del derecho al Estado. El objeto del derecho consistiría en una acción negativa que prohibiría al Estado, prima facie, afectar la situación de incomunicación patrimonial entre los accionistas y la sociedad.

La construcción de tal derecho conduce a la Corte a aceptar su naturaleza relativa o limitada y, en consecuencia, a admitir que es factible imponer a su ejercicio algunas restricciones. Tales restricciones, considerando que la constitución de una sociedad anónima es la manifestación del derecho de asociación, se fundamentan en las mismas razones previstas para la restricción del derecho de asociación en general.

En este sentido el derecho de los accionistas a la incomunicación patrimonial puede verse restringido, según la sentencia, (a) por la necesidad de salvaguardar los derechos de los demás y de impedir su desarrollo abusivo como medio de defraudación o engaño y (b) en interés de preservar la moral pública, la seguridad nacional, la seguridad jurídica y el orden público.

e. El quinto nivel de la argumentación que desarrolla la sentencia se orienta a determinar si la Constitución define un determinado régimen societario que exija, por ejemplo, un especial nivel de intensidad de la incomunicación patrimonial y, en consecuencia, un sistema específico de responsabilidad de los accionistas de la sociedad anónima.

La Corte, tal y como se señaló en el literal (B) de esta síntesis, afirma que en el Congreso está radicada una amplia competencia para definir las cuestiones relacionadas con tales asuntos. No obstante, si bien la sentencia admite que el legislador puede definir diferentes 
tipos de sociedades con diversos niveles de riesgo, también establece que al Congreso le corresponde - lo que equivale a que el Congreso debe - preservar los atributos de la sociedad ${ }^{33}$.

El citado deber, prima facie, de preservar los atributos de la sociedad tiene como correlato el derecho - no definitivo - de los accionistas a que no se afecte su situación de incomunicación patrimonial. La articulación de tales posiciones iusfundamentalmente adscritas parece conducir a la Corte a la estructuración de una regla con el siguiente contenido:

(R1) Los accionistas de las sociedades anónimas tienen el derecho constitucional a la conservación de su situación de incomunicación patrimonial. Tal derecho deberá ser restringido por el legislador a través del establecimiento de un régimen de responsabilidad que deberá (a) formularse a partir de circunstancias especiales y específicas que exijan tal tipo de restricciones, (b) respetar los principios, valores y derechos de la Constitución y (c) sujetarse a las exigencias derivadas de los principios de proporcionalidad y razonabilidad.

f. En el siguiente paso, la Corte expone razones adicionales que fortalecen la vinculación constitucional del derecho de los accionistas a que se respete la incomunicación patrimonial. En efecto, (a) desarrollando una aproximación a la Constitución económica, (b) exponiendo la importancia histórica de las sociedades por acciones - específicamente la sociedad anónima - y (c) destacando la importancia de la separación patrimonial en la determinación del valor de las acciones, la providencia indica que la ausencia de tal separación pondría en riesgo el adecuado funcionamiento del mercado público de valores al que se articulan procesos de circulación de riqueza de gran relevancia ${ }^{34}$.

\footnotetext{
${ }^{33}$ Fundamento Jurídico 18.

${ }^{34}$ Se expresa así la Corte en el fundamento jurídico 22 de la sentencia que se analiza: "La canalización de recursos financieros a través de acciones constituye una típica fórmula de inversión social y económica. Es inversión económica, pues los grandes capitales logran realizar importantes proyectos económicos en beneficio del país. Es inversión social, ya que la empresa constituye no solo el principal generador de empleo y bienestar, sino también el mayor contribuyente fiscal del Estado".
} 
De esta manera, el derecho de los accionistas que se ha mencionado ostenta una doble adscripción. Por una parte, como se dijo, se deriva de la norma iusfundamental que consagra el derecho de asociación. Por otra parte, se adscribe a las exigencias que se derivan de algunas de las normas no iusfundamentales que disciplinan la Constitución económica.

Con apoyo en tales argumentos la Corte recoge en un párrafo el argumento definitivo: "Así las cosas, si las personas jurídicas de riesgo limitado son pilares estructurales para el desarrollo del país, no admite discusión alguna que el hecho de asistir al desaparecimiento de sus atributos, pondría en riesgo la estabilidad y el orden económico como fines esenciales del Estado, previstos tanto en el preámbulo como en los artículos $1^{\circ}$, 25, 39, 150-8, 189 24, 333 y 334 de la Constitución Política" (Fundamento Jurídico 22).

f. Considerando el contenido de la regla 1 (R1) que señala que el legislador (i) no sólo debe garantizar el derecho de los accionistas a la separación patrimonial (ii) sino también restringir tal derecho cuando las circunstancias lo exijan, el Tribunal Constitucional colombiano, de manera claramente coincidente con la doctrina del levantamiento del velo corporativo que se ha examinado más arriba (2.1), establece que "cuando se vulnera el principio de buena fe contractual y se utiliza a la sociedad de riesgo limitado no con el propósito de lograr un fin constitucional válido, sino con la intención de defraudar los intereses de terceros, entre ellos, los derechos de los trabajadores, es que el ordenamiento jurídico puede llegar a hacer responsables a los asociados, con fundamento en una causa legal distinta de las relaciones que surgen del contrato social. Es entonces -continua la Corte- en la actuación maliciosa, desleal o deshomesta de los accionistas generadora de un daño para con los terceros, en donde se encuentra la fuente para desconocer la limitación de la responsabilidad y exigir de los socios la reparación del daño acontecido" (Fundamento Jurídico 25).

En consonancia con lo anterior y al emprender el análisis específico del problema jurídico formulado por los demandantes, la Corte Constitucional establece que el artículo 373 del Código de Comercio no autoriza el empleo de la personificación jurídica correspondiente a la sociedad anónima como instrumento para desconocer los derechos de los trabajadores y pensionados (Fundamento Jurídico 29).

Este razonamiento admite que el empleo de la sociedad con finalidades de defraudación de los trabajadores resultaría inconstitucional. Esto implica que la ausencia de un mecanismo para interferir en la incomunicación patrimonial determinaría la inconstitucionalidad de 
la norma. Sin embargo, la Corte Constitucional constata la existencia en el ordenamiento jurídico de múltiples mecanismos de protección de los intereses de los trabajadores, algunos de los cuales son un desarrollo efectivo de la teoría del levantamiento corporativo. Así mismo destaca la manera en que la jurisprudencia constitucional ha definido el empleo de ciertos mecanismos para proteger los derechos de los trabajadores, tal y como ocurrió en los casos resueltos mediante las sentencias SU-1023 de 2001 y SU-636 de 2003, las cuales se analizarán en el siguiente aparte.

Adicionalmente es necesario destacar que el legislador dispone de una amplia gama de opciones en esta materia, y por lo tanto no se le impone levantar el velo corporativo en toda situación de conflicto entre la sociedad y los derechos de terceros.

Ello no quiere decir que su actuación resulte constitucionalmente indiferente, sino que el legislador puede adoptar medidas equivalentes que pueden no consistir en el desconocimiento de la separación patrimonial.

La sentencia C-865 de 2004 resulta de gran importancia debido a que en ella la Corte define constitucionalmente un problema que, hasta ese momento, no había sido tratado con tal intensidad. Esta decisión, complementa, en alguna medida, la jurisprudencia desarrollada por la Corte en las sentencias SU-1023 de 2001 y SU636 de 2003.

Aunque no lo logra con la claridad deseada, la sentencia trata de definir algunos márgenes de acción con los que cuenta el legislador para regular las tensiones constitucionales que se presentan en las relaciones jurídicas externas de las sociedades de separación patrimonial absoluta. Tal definición será analizada, brevemente, en el aparte (5) de este trabajo. Por ahora es suficiente con afirmar que la decisión examinada se traduce en una manifestación del proceso de constitucionalización del derecho societario y en la necesidad de abordar sus problemas a partir de tal nivel.

\section{El principio de limitación del riesgo en las sociedades anónimas y la} responsabilidad subsidiaria de las sociedades matrices

Las circunstancias que rodearon los dos casos resueltos en las sentencias SU1023 de 2001 ("Viuda de Fajardo y otros contra Flota Mercante Gran Colombiana") y SU-636 de 2003 ("Luis Mesa Marín y otros contra Sociedad Industrial Hullera S.A") son similares en sus aspectos esenciales. De igual manera, la línea argumentativa 
seguida en ambas providencias, así como las decisiones allí adoptadas por la Corte Constitucional, se diseñan de idéntica manera.

Los supuestos, de hecho, podrían formularse a partir de la presentación de cuatro enunciados generales: (1) La sociedad -A-, en estado de liquidación, se ha encontrado sometida al control de otro ente societario -B- o no societario -C- (2) La sociedad -A- ha dejado de satisfacer el pago de las mesadas pensionales y, como consecuencia de ello, no se ha producido el pago de los aportes al Sistema de Seguridad Social en Salud. (3) La sociedad - A- carece de la liquidez para cancelar el valor de las mesadas pensionales. (4) Los pensionados interponen acciones de tutela a fin de que se ordene el pago inmediato de las pensiones. Dichas acciones se dirigen en ocasiones contra A o contra B-C, o contra ambos conjuntamente.

En lo que interesa, la línea argumentativa de la Corte Constitucional se desarrolla a través de un razonamiento compuesto por tres gradas.

En la primera de ellas se sostiene el carácter fundamental del derecho a recibir la mesada pensional dada su vinculación con el derecho al mínimo vital, al trabajo y al deber especial de protección a las personas de la tercera edad. Dicho argumento se complementa con la constatación relacionada con el hecho de que las personas que requieren el pago de sus mesadas pensionales no se encuentran en capacidad de reincorporase al mercado laboral.

En la segunda, debido a que el no pago de las mesadas pensionales afecta los derechos fundamentales ya mencionados, la Corte Constitucional acepta la procedencia de la tutela como mecanismo transitorio, sin que para tal determinación tengan incidencia las facultades de la Superintendencia de Sociedades en el proceso de liquidación respectivo.

Finalmente, en la última grada del argumento, la Corte Constitucional sostiene que la situación de iliquidez de la sociedad filial justifica que, en aplicación de la presunción contemplada en el artículo 148 de la ley 222 de 1995, se obligue a la(s) sociedad(es) controlante(s) ${ }^{35}$ a asumir, de manera subsidiaria, el pago de las mesadas pensionales.

\footnotetext{
${ }^{35}$ En la sentencia SU-636 de 2003 se acepta que las sociedades Coltejer S.A., Fabricato S.A. y Cementos el Cairo S.A. han ejercido un control conjunto de la sociedad Industrial Hullera S.A., declarado por la Superintendencia de Sociedades. Dicho control fue reconocido, adicionalmente, por la Sección Primera del Consejo de Estado, mediante sentencia dictada el 27 de marzo de 2003.
} 
El último nivel del razonamiento desarrollado por la Corte Constitucional es el que resulta más problemático desde el punto de vista del derecho comercial y del derecho societario, debido a cuatro razones fundamentales: (1) En desarrollo de un proceso constitucional de tutela caracterizado por su brevedad, la Corte Constitucional, luego de hacer efectiva (con fundamento en la segunda parte del parágrafo del artículo 148 de la ley 222 de 1995) la presunción de que la situación concursal en que se encuentra una sociedad filial ha sido el producto del control ejercido, determina que los entes controlantes deben asumir, al menos transitoriamente, el pago de las mesadas pensionales correspondientes. (2) Parece acudirse a un sistema de responsabilidad objetiva a fin de vincular al pago de los pasivos laborales a los entes matrices. Por esta vía, se estarían desconociendo las bases que autorizan la remoción del velo corporativo ${ }^{36}$. (3) Lo que realmente determina el parágrafo del artículo 148 de la ley 222 de 1995 no es una responsabilidad presunta sino una presunción del nexo causal de la responsabilidad ${ }^{37}$. (4) Debido a que la inversión económica a través de la participación en sociedades de capital se encuentra motivada, fundamentalmente, por la seguridad que la personificación jurídica le brinda al patrimonio de los accionistas, una decisión como la formulada por la Corte Constitucional es inaceptable debido a que tiene por efecto eliminar un factor que impulsa los procesos de inversión y creación empresarial.

La ampliación de la responsabilidad de los accionistas de una sociedad anónima resulta, en cualquier caso, ciertamente problemática. Al definir los rasgos característicos de la sociedad anónima, el profesor Gabino Pinzón aclara: "Se trata, ante todo, de una sociedad en la que el fondo social representa la única garantía de los terceros que contratan con ella. Esta es la primera y principal consecuencia de la limitación de la responsabilidad de los asociados a sus respectivos aportes" ${ }^{\prime 38}$.

\footnotetext{
${ }^{36}$ El profesor Reyes Villamizar ha sostenido en un reciente artículo lo siguiente: "Es cierto que las legislaciones de vanguardia denotan una notoria preocupación por preservar el principio de limitación de riesgo propio de las sociedades de capital, aunque este dogma puede atenuarse mediante la tesis del descorrimiento del velo societario. Pero esto último solo puede ocurrir en aquellos casos en que se ha presentado fraude, simulación, infracapitalización, abuso del derecho u otras conductas reprochables en el control de la sociedad. La valoración del comportamiento de quien debe responder es, pues, una característica universal de allanamiento de la personalidad jurídica de la sociedad", Periódico Ámbito Jurídico, Editorial Legis, No. 159 (16 al 29 de agosto), pág. 13A ${ }^{37}$ Un conjunto de críticas al contenido de la sentencia SU-1023 de 2001 puede encontrarse en Francisco Reyes Villamizar, Derecho Societario, Ed. Temis, 2002, pags. 556 a 559.

${ }^{38}$ Gabino Pinzón, Sociedades Comerciales VOL. II, Ed Temis, 1983, pág 155 y 156. Allí continua el autor citado: "Los terceros carecen de toda acción contra el accionista, como tal, puesto que, aunque este no haya pagado sus acciones, es la sociedad la única que puede hacer efectivo ese crédito correspondiente a la obligación del asociado; y una vez pagadas las acciones, ni siquiera la sociedad misma puede compeler al accionista a que aumente o reponga su aporte". El profesor Norbert Reich se ha referido a las sociedades de capital en los siguientes términos: "Las sociedades de capitales, en cambio, se organizan en forma de personas jurídicas
} 
En consecuencia, es claro que las sentencias SU-1023 de 2001 y SU-636 de 2003, aunque pueden generar dudas sobre la corrección de los argumentos en los que se sostienen, influyen sobre la definición del alcance del principio de limitación de la responsabilidad en las sociedades de capital. De esta manera, puede afirmarse que a las providencias mencionadas, al igual que a la sentencia C-865 de 2004, subyace la pretensión de constitucionalizar una controversia mercantil relacionada, en general, con la responsabilidad de los accionistas de las sociedades anónimas y, en particular, con la responsabilidad de los entes controlantes -matrices- respecto de las obligaciones pensionales de sus filiales ${ }^{39}$.

De conformidad con el anterior aserto, se abre paso el cuarto nivel del presente ensayo, siendo el momento de explorar, brevemente, la capacidad de la dogmática de los márgenes de acción para permitir (a) la explicación jurídico-constitucional adecuada de la sentencia C-865 de 2004, (b) la exposición clara de los alcances de las controversias suscitadas por las sentencias SU-1023 de 2001 y SU-636 de 2003 y (c) para fundamentar la manera como debe explicarse el alcance normativo relacionado, del derecho comercial y del derecho constitucional.

\section{La dogmática de los márgenes de acción como sistema orientador y explicativo de un proceso de constitucionalización correcto.}

La dogmática de los márgenes de acción sostiene que la Constitución, a la vez que expresa (a) un orden fundamental, define igualmente (b) un orden marco. Según ese concepto, la Constitución es un orden fundamental porque pretende resolver los problemas fundamentales de una comunidad. Sin embargo, y dado que la Constitución no contiene respuestas definitivas sobre cada uno de los problemas jurídicos posibles, representa un orden marco en la medida en que a partir de ella se define (1) lo constitucionalmente necesario u ordenado y (2) lo constitucionalmente imposible o prohibido, dejando, en consecuencia, un margen para (3) lo constitucionalmente discrecional o permitido.

y descansan sobre el principio de separación entre la condición de miembro y la posesión directa de los objetos que constituyen su capital productivo. Sus miembros, socios y accionistas, poseen derechos sociales y patrimoniales en función de su cuota de aportación a la sociedad, apareciendo la persona jurídica como único titular del patrimonio productivo y, como tal, como auténtico sujeto de los procesos de mercado", Mercado y Derecho, Editorial Ariel, Barcelona, 1985, pags. 272 y 273.

${ }^{39}$ En mi opinión, resulta lamentable que la crítica recientemente formulada por el profesor Reyes Villamizar se abstenga de toda consideración en relación con la relevancia de los intereses constitucionales en juego. 
Considerando a la Constitución como un orden marco en el sentido mencionado $^{40}$ es evidente que la misma no determina definitivamente el sentido de todas las decisiones jurídicas concretas y, en este orden de ideas, existe un espacio de decisión discrecional o permitido ${ }^{41}$ que o bien le atañe al legislador, o bien le corresponde al juez ordinario o, es posible, le incumbe a la administración o a los particulares a través de su capacidad de regulación. La determinación de ese espacio es precisamente de lo que se ocupa la dogmática de los márgenes de acción. Tal dogmática busca establecer, a partir del reconocimiento de principios formales de distribución de competencias, qué cuestiones del ordenamiento jurídico no han sido constitucionalizadas y por lo tanto no les corresponde decidir a los Tribunales Constitucionales.

Según las orientaciones generales de dicha dogmática existen dos tipos básicos de márgenes de acción. De una parte, el margen de acción estructural "se forma a partir de los límites de aquello que la constitución ordena y prohíbe"42. De otra parte, los márgenes de acción epistémicos se configuran "a partir de los límites de la capacidad para reconocer lo que la Constitución por una parte, ordena y prohíbe, y por otra, no ordena ni prohíbe"43. Lo que se encuentra dentro de tales límites hace parte de un margen de acción.

La complejidad de los supuestos básicos de la dogmática de los márgenes de acción impide abordarla en toda su extensión en este lugar. Es suficiente con precisar que tal dogmática pretende clarificar los ámbitos de decisión que

\footnotetext{
${ }^{40} \mathrm{R}$. Alexy, sostiene sobre el particular lo siguiente: "Una constitución es un orden fundamental cualitativo, si resuelve aquellas preguntas fundamentales para la comunidad que pueden y deben estar resueltas en la Constitución. Este concepto de orden fundamental es compatible con el de orden marco. Una constitución puede resolver asuntos fundamentales, y en ese sentido ser un orden fundamental, y, sin embargo, dejar muchas preguntas sin responder y por tanto ser un orden marco", Robert Alexy, Tres escritos... Cit, p. 56. Sobre una idea semejante a la expuesta y vinculando su argumento a un tipo especial de interpretación de la Constitución, Ricardo Guastini sostiene lo siguiente: "Si se esta inclinado por la interpretación literal (y por el argumento a contrario), ninguna Constitución resulta completa: antes bien, cualquier Constitución no regula más que una pequeña parte de la vida política y social. Existe, por lo tanto, una vasta parte de la vida social y política que no es regulada, a nivel constitucional, pornorma jurídica alguna", La Constitucionalización...Cit, p. 54.

${ }^{41}$ Lo discrecional no equivale a lo arbitrario. En todo caso las decisiones discrecionales del legislador o del juez ordinario deben apoyarse en argumentos intersubjetivamente controlables. Simplemente, lo discrecional equivale a sostener que el legislador o el juez gozan de una facultad más o menos amplia de solución o interpretación de un asunto definido.

${ }^{42}$ Robert Alexy, Tres escritos... Cit, p. 89. Existen tres márgenes de acción estructural: (a) para la fijación de fines, (b) para la elección de medios y (c) para la ponderación.

${ }^{43}$ Robert Alexy, Tres escritos... Cit, p. 89. Existen márgenes de acción epistémicos de tipo empírico y márgenes de acción epistémicos de tipo normativo.
} 
se encuentran excluidos del control constitucional ordinario ${ }^{44}$, debido a que (a) o no han sido decididos en la constitución (margen de acción estructural) o (b) la determinación de si tal decisión ha sido adoptada no resulta posible (margen de acción epistémico). Para los objetivos que persigue este ensayo y para el análisis del problema del que me ocuparé a continuación es suficiente con referirse al margen de acción estructural para ponderar ${ }^{45}$.

Todo problema jurídico puede suponer la constatación del enfrentamiento de dos o más intereses. Cuando ello ocurre es necesario acudir a un procedimiento que resulte racionalmente controlable a fin de establecer cuál de los intereses ostenta un mayor peso y, en consecuencia, se erige en razón para la restricción de otro. Tal procedimiento, denominado ponderación, se rige por una ley de conformidad con la cual "cuanto mayor sea el grado de no realización $o$ afectación de un principio, tanto mayor tiene que ser la importancia de la satisfacción del otro" ${ }^{\prime 4}$.

De esta manera, cuando debe llevarse a cabo una ponderación es necesario desplegar tres exámenes diferentes. Primeramente (a) debe determinarse el grado de no realización o afectación de un principio, a continuación (b) es necesario constatar el grado de la importancia de la satisfacción del otro principio en juego y, finalmente, (c) se requiere una comparación de ambos grados. Si de esta última comparación resulta que la no realización de un principio es alta y la importancia de la satisfacción del otro no es tan grave (media o leve), resultaría que la restricción que se propone es desproporcionada y, en este sentido, no se encontraría autorizada por el ordenamiento jurídico. Si por el contrario, de la comparación efectuada resulta que la importancia de la satisfacción es igualmente alta, la autoridad correspondiente gozaría de un margen de acción estructural dado que la ponderación no conduce a una conclusión definitiva ${ }^{47}$.

\footnotetext{
${ }^{44}$ Con la expresión control constitucional ordinario se hace referencia al control ejercido por la Corte Constitucional y, en general, por la jurisdicción constitucional a través de los mecanismos institucionales y judiciales especialmente previstos para ello.

${ }^{45}$ Sobre el concepto de ponderación puede consultarse, Robert Alexy, Tres escritos... Cit, p. 101 y ss.. Así mismo Robert Alexy, Teoría ..., Cit, p. 157 y ss.

${ }^{46}$ Robert Alexy, El concepto..., Cit, p. 171.

${ }^{47}$ Una revisión analítica importante de la ponderación como procedimiento para interpretar los derechos fundamentales puede encontrarse en, Carlos Bernal Pulido, El Derecho de los derechos, Primera Parte-Capitulo Tercero, Universidad Externado, 2005, Págs. 95 y ss.
} 
Podría examinarse, antes de continuar con el siguiente paso, el contenido del artículo 524 del Código de Comercio a fin de definir la existencia de un margen de acción estructural para la ponderación. Según este artículo, quienes realizan un contrato de arrendamiento de un local comercial tienen prohibido fijar un término de desahucio inferior a seis meses ${ }^{48}$. A partir de esto, se pueden estimar las siguientes consideraciones: Una, en el sentido de que tal prohibición tiene como finalidad la protección de la estabilidad de la actividad empresarial del arrendatario y el otorgamiento de un plazo para acomodarse a la nueva situación; y otra, que con tal prohibición se restringe el principio de libertad negocial dado que los contratantes no podrían pactar un término inferior para el desahucio.

Llevando a cabo un análisis de ponderación podría sostenerse lo siguiente: (1) El grado de no realización del principio de la autonomía negocial podría catalogarse como medio dado que no existe una prohibición completa de desahucio ni obstáculo alguno para acordar un término superior si así lo convienen las partes. (2) El grado de importancia del principio de protección a la estabilidad empresarial podría, igualmente, catalogarse como medio, dado que dicha protección, aunque importante, no es esencial para que el comerciante pueda desarrollar su actividad. (3) En este sentido, se puede constatar un empate entre ambos grados y, en consecuencia, afirmarse la existencia de un margen de acción estructural para la ponderación que consiste en otorgarle al legislador mercantil la autorización de prescribir o no límites temporales para el desahucio, sin que pueda afirmarse que la Constitución le ha ordenado o prohibido hacerlo ${ }^{49}$. Lo anterior equivale a decir que la solución de este problema desde el punto de vista constitucional no ha sido resuelta definitivamente y, por ello, no le corresponde a un Tribunal Constitucional definir una orientación específica ${ }^{50}$.

Así las cosas, resulta clara la posibilidad, a través la dogmática de los márgenes de acción, de establecer pautas racionalmente controlables para limitar y definir la manera en que la constitucionalización del derecho mercantil debe llevarse a cabo.

\footnotetext{
${ }^{48}$ Para aquellos eventos contemplados en los numerales 2 y 3 del artículo 518 del Código de Comercio.

${ }^{49}$ No obstante, es posible argumentar que la decisión acerca de la existencia de un plazo de desahucio excesivamente reducido podría no caer dentro de un margen de acción debido a los intereses constitucionales que un regulación tal podría desencadenar.

${ }^{50}$ En este sentido se trataría de una preferencia por el principio democrático. En el trabajo de Carlos Bernal Pulido, citado en la nota de pie No. 47, se aborda la eventual contradicción entre las posiciones defendidas por Alexy en el último capitulo de su Teoría de los Derechos Fundamentales y en el Epilogo a tal Teoría.
} 
A fin de explorar con mayor cuidado tal posibilidad, a continuación se estudiarán (a) las consideraciones de la sentencia C-865 de 2004 sobre la constitucionalidad del artículo 373 del Código de Comercio y (b) el debate suscitado por las sentencias SU-1023 de 2001 y SU-636 de 2003 de la Corte Constitucional, para revisar cómo la dogmática de los márgenes de acción puede explicar satisfactoriamente las decisiones allí adoptadas.

\section{El margen estructural para la ponderación: Entre el respeto incondicio-} nado de la personalización jurídica societaria y la efectividad de los derechos fundamentales de los pensionados

Una vez (i) constatada la constitucionalización de una disputa relevante, prima facie, para el derecho comercial y (ii) constatada la tensión entre varios principios derivados del texto constitucional, es necesario llevar a cabo una ponderación para definir si sobre dicho aspecto la Constitución se pronuncia definitivamente, o si, por el contrario, deja un margen de acción estructural para que el legislador regule la materia. A la luz de tales premisas se desarrollan las cuestiones siguientes:

5.1 La Sentencia C-865 de 2004 y la inexistencia de un margen de acción general- estructural para la ponderación.

La sentencia C-865 de 2004 plantea la tensión entre dos exigencias que tendrían un claro fundamento constitucional. De una parte, (D1) el derecho de los accionistas de sociedades anónimas a la conservación de su situación de incomunicación patrimonial (fundamentado en la norma que consagra el derecho de asociación y en la Constitución económica) y, de otra, (D2) los derechos o intereses de personas u organizaciones relacionadas externamente con la sociedad a que no se desconozcan sus intereses a través del empleo fraudulento del principio de limitación del riesgo (fundamentado, entre otros, en el principio de la buena fe $)^{51}$.

Las consideraciones de la Corte Constitucional, como se verá, plantean el diseño de un margen de acción que le permite al legislador definir las medidas necesarias para proteger los derechos en juego. Tal margen se construye a partir de la formulación de un mandato y de una prohibición ${ }^{52}$, cuyo destinatario principal sería el legislador. Tales normas podrían presentarse en los siguientes términos:

\footnotetext{
${ }^{51}$ Cada uno de los derechos de los terceros podrá tener un fundamento constitucional diferente. Por ejemplo, no será idéntico fundamento el presentado por un grupo de trabajadores o pensionados que el aducido por el Estado en ejercicio de sus competencias en materia tributaria.

52 Si bien, como ha sido reconocido por la teoría jurídica, los operadores deónticos de mandato y prohibición son intercambiables a través del empleo del concepto de omisión, por razones de claridad en el trabajo se emplean ambas categorías normativas.
} 
(M1) Al legislador le está ordenado, constitucionalmente, garantizar la existencia de instituciones jurídicas que permitan desarrollar cauces adecuados de producción de inversión, riqueza y empleo.

Este mandato, con un nivel mayor de especificidad tendría la siguiente estructura:

(M2) Al legislador le está ordenado, constitucionalmente, garantizar la vigencia de órdenes jurídicos que respalden la creación de sociedades por acciones y que reconozcan el principio de separación patrimonial, dado que las mismas permiten desarrollar los cauces indicados en $\mathrm{M} 1^{53}$.

La prohibición que impone restricciones al derecho sobre el cual se estructuran M1 y M2 se formularía así:

(P1) Al legislador le está prohibido, constitucionalmente, abstenerse de adoptar medidas encaminadas a proteger los derechos e intereses de los terceros que se relacionan con una sociedad anónima, cuando la persona jurídica que nace de su constitución y la separación patrimonial que ello conlleva ha sido empleada para ejecutar acciones contrarias al principio de la buena fe.

Expresada de manera más específica, la prohibición sería del siguiente tipo:

(P2) Al legislador le está prohibido, constitucionalmente, abstenerse de regular instituciones jurídicas que permitan la protección de los derechos e intereses de los terceros que se relacionan con una sociedad anónima y, en especial, que garanticen los derechos de los trabajadores y los pensionados, cuando la persona jurídica que nace de su constitución y la separación patrimonial que ello conlleva ha sido empleada para ejecutar acciones contrarias al principio constitucional de la buena fe.

En este lugar no interesa el tipo de deberes y derechos que podrían adscribirse, prima facie, a cada uno de los mandatos y prohibiciones presentados.

\footnotetext{
${ }^{53}$ Este mandato no se opone que el legislador, en caso de existir mecanismos con el mismo nivel de efectividad para alcanzar las finalidades a que alude M1, en ejercicio de su potestad de configuración elija estructurar sistemas empresariales diferentes.
} 
Lo que sí resulta importante es señalar que las prohibiciones, a partir de la articulación de M1 y M2 con D2, se encuentran estructuradas sobre la base de una ponderación de los derechos (D1) y (D2) arriba mencionados.

De acuerdo con lo anterior, de la Constitución no se seguiría un margen de acción estructural para la ponderación en estos casos dado que, siempre que se configure el supuesto de hecho $(\mathrm{SH})$ subrayado en $\mathrm{P} 1$ y $\mathrm{P} 2$, el derecho (D2) precede al derecho (D1). Esto quiere decir que la importancia de realización de D1 puede considerarse superior al grado de no realización de $\mathrm{D} 2$. Así las cosas, el principio constitucional de la buena fe incluido en (SH) es una razón fundamental para orientar el sentido de la ponderación que efectuó la Corte Constitucional en la sentencia C-865 de 2004.

No obstante lo indicado, es necesario hacer dos precisiones adicionales. En primer lugar, la inexistencia de un margen de acción estructural según P1 y P2 no implica que en cada caso no deba evaluarse el tipo de intereses constitucionales comprometidos en el debate. Dependiendo de quiénes hayan sido los defraudados por la sociedad anónima, la argumentación podrá ser diferente. Sin desconocer que la restricción de la separación patrimonial va ligada al principio de la buena fe, dicha restricción no podrá justificarse de la misma manera si el tercero afectado es un trabajador, el Estado, una entidad administradora de recursos parafiscales o un proveedor determinado. En este sentido, el contenido de los razonamientos podrá tener una estructura diferenciada.

Quizás alguien afirmaría que la precisión anterior resulta irrelevante dado que el supuesto de hecho $(\mathrm{SH})$ siempre conduce a la misma conclusión. No obstante -y esta es la segunda precisión-, considerando (a) el ámbito en el cual la sociedad anónima es empleada para defraudar expectativas legitimas de terceros y, en consecuencia, (b) el tipo de razones que se presentan para justificar la aplicación de P1 y P2, las medidas que puede adoptar el legislador serán diferentes. Ello quiere decir que las restricciones del derecho a la separación patrimonial podrán tener un menor o mayor grado, según el ámbito en que se despliegue tal derecho. Por lo tanto, el legislador goza en esta materia no de un margen de acción estructural-general para la ponderación, sino de un margen estructural para la elección de los medios para proteger los derechos de terceros, el cual se articula con un espectro de márgenes de acción estructurales-especiales para la ponderación. Es decir, al legislador no le corresponde decir si P1 o P2 son correctos constitucionalmente, sino si la medida limitadora del derecho de los accionistas es más o menos intensa. De esta manera, los medios elegidos podrían no consistir en medidas que 
desarrollen la doctrina del levantamiento corporativo, siempre y cuando resulten idóneas para alcanzar los objetivos correspondientes.

Debo señalar, por ahora, que la naturaleza de los mencionados márgenes de acción estructurales-especiales para la ponderación es prima facie, dado que es posible que a medida que la jurisprudencia constitucional aborde la materia considere que algunas de tales cuestiones han sido resueltas definitivamente por la Constitución.

Por lo tanto, de las prohibiciones P1 y P2 no puede derivarse la aplicación de la teoría del levantamiento del velo corporativo en todos los casos. La aplicación de dicha teoría solo resultará imperativa en aquellos eventos en que se concluya que otra elección no puede garantizar adecuadamente los intereses en juego.

A la luz de estas consideraciones es importante establecer la utilidad de la dogmática de los márgenes de acción para comprender los argumentos formulados en las sentencia SU-1023 de 2001 y SU-636 de 2003.

\subsection{Las sentencias SU-1023 de 2001 y SU-636 de 2003 y la elimina-} ción de de un margen de acción estructural-especial de ponderación

El problema básico abordado en las sentencias que han sido analizadas supone el conflicto entre (a) el principio que reconoce y protege la autonomía de la voluntad, la libertad de empresa, la capacidad para diseñar organizaciones societarias a fin de participar activamente en una economía de mercado y, en particular, el derecho de los accionistas de sociedades anónimas a la conservación de su situación de incomunicación patrimonial, y (b) el principio que garantiza la efectividad de los derechos fundamentales al mínimo vital ${ }^{54}$, al trabajo y a la especial protección de los pensionados, conjuntamente con el principio que protege los derechos de los terceros que se relacionan con una sociedad anónima que emplea la separación patrimonial como medio para defraudarlos.

La Corte Constitucional sostiene que la importancia de los derechos efectivos al mínimo vital, al trabajo y a la protección justifica la restricción impuesta a la capacidad para diseñar libremente sistemas societarios. Tal

\footnotetext{
${ }^{54}$ Para analizar la evolución del derecho al mínimo vital, puede consultarse Jurisprudencia constitucional sobre el derecho al mínimo vital -Directores: Rodolfo Arango y Julieta Lemaitre-, Estudios Ocasionales CIJUS, Universidad de los Andes, 2003.
} 
restricción permite afirmar, por medio de una acción de tutela, la configuración de la presunción del nexo causal de responsabilidad contemplado en el artículo 148 de la ley 222 de 1995. A partir de allí es posible sostener la responsabilidad de los entes que ostentan el carácter de matrices o controlantes de la sociedad deudo$\mathrm{ra}^{55}$. Tal conclusión permite remover el velo corporativo y ampliar la responsabilidad de aquellos accionistas que, acudiendo a la legislación propia de las sociedades de capital, han querido limitar su responsabilidad.

Es posible considerar que para la Corte Constitucional tal restricción se justifica debido a que el grado de afectación de los principios vinculados directamente a la actividad empresarial alcanzaría un nivel intermedio, el cual debe ceder frente al grado de importancia alto que tienen las normas iusfundamentales.

Tal argumentación implica que, en hipótesis como las que ocuparon la atención de la Corte Constitucional, no existe ni siquiera un margen de acción estructural-especial para la ponderación (según el sentido que le doy a esta expresión en 5.1), ni tampoco un margen de acción estructural para la elección de medios. Esto se debe a que la situación de la sociedad controlada y los derechos de los trabajadores y pensionados en juego impiden abstenerse de adoptar las medidas inmediatas que permitan satisfacer tales derechos. En esos casos, la estrategia de protección debe tener efectos jurídicos inmediatos, dado que ni las autoridades públicas ni los particulares pueden permitir la extensión en el tiempo de la violación de los derechos de los trabajadores y pensionados.

Debe advertirse que en este caso la resultante limitación del derecho de los accionistas a la separación patrimonial ${ }^{56}$ tenía como finalidad deparar una protección inmediata a los derechos mencionados. Es decir, no se imponía, necesariamente, el levantamiento del velo corporativo, sino el empleo de una medida efectiva para la protección de los derechos cuya vulneración se había constatado. La Corte consideró que la aplicación de la presunción contenida en la norma citada le permitía tomar dicha decisión, incluso al margen de la evaluación de la buena o mala fe de los accionistas controlantes. Así las cosas, resulta claro que si hubiesen existido medidas alternativas de mayor o igual eficacia, previo el examen constitucional correspondiente, la Corte hubiese podido optar por su empleo.

\footnotetext{
${ }^{55}$ De conformidad con las condiciones previstas, entre otros, en los artículos 26 y 27 de la ley 222 de 1995.

${ }^{56} \mathrm{La}$ Corte Constitucional levantó el velo corporativo amparándose en lo dispuesto en el articulo 148 de la ley 222 de 1995.
} 
Así, de una parte, el legislador carece de competencia para regular el desarrollo de los sistemas concursales de una forma que conduzca a un resultado diferente $^{57}$ al planteado por la Corte Constitucional; de otra, la superintendencia de sociedades no tiene la autonomía interpretativa para limitar, en casos como estos, la responsabilidad de los asociados controlantes, por lo que deberá interpretar el parágrafo del articulo 148 en la forma en que lo definió la Corte Constitucional.

En consecuencia, una disputa que originalmente se asumía como estrictamente mercantil adquiere un significado diferente una vez se sostiene su relevancia constitucional. Se concluye, por lo tanto, que no hace parte de un margen de acción estructural sino que, precisamente, juega un papel importante en la delimitación de dicho margen. Así las cosas, solo restaría proceder a presentar un conjunto de tesis básicas que permitirían revitalizar adecuadamente las relaciones entre el derecho comercial y el derecho constitucional.

6. Siete tesis acerca de la dogmática de los márgenes de acción como estrategia argumentativa para revitalizar las relaciones entre el derecho mercantil y el derecho constitucional

Las relaciones entre el derecho comercial y el derecho constitucional no se limitan a la existencia de una Constitución económica que protege la iniciativa privada y promueve a la empresa. La Constitución como fundamento de la totalidad del ordenamiento, expresa, adicionalmente, la pretensión de constitucionalizar el derecho comercial a través de la expansión de los contenidos iusfundamentales y no iusfundamentales. Para llevar a cabo un proceso de expansión constitucional correcto es indispensable conocer y ser consciente de los alcances y límites del mismo. En consecuencia, es necesario, como conclusión, considerar las siguientes siete tesis:

a. La Constitución ostenta la naturaleza de orden fundamental y orden marco. Ello quiere decir, por un lado, que resuelve las cuestiones jurídicas fundamentales de una comunidad y, por otro, que lo anterior no implica que pueda dar respuesta definitiva a todos los problemas jurídicos.

b. La Constitución resuelve las preguntas esencialmente fundamentales para el derecho comercial y confiere un margen de acción a los poderes públicos y a los particulares para definir la orientación de la solución de los otros problemas.

${ }^{57}$ Un resultado diferente consistiría en la ausencia de protección inmediata de los derechos de los trabajadores y pensionados 
c. La determinación de lo fundamental al derecho comercial que ha sido resuelto por la Constitución corresponde, en el caso colombiano, a la Corte Constitucional, pues este es el tribunal que ha sido diseñado para garantizar la integridad y supremacía de la misma.

d. La existencia de dicha competencia no supone que tal definición pueda ser llevada a cabo arbitrariamente. Si bien la naturaleza prima facie indeterminada de las normas de derecho fundamental representa una dificultad importante para establecer lo constitucionalmente resuelto, el principio de proporcionalidad confiere bases sólidas para llevar a cabo tal tarea.

e. La posibilidad de determinar si una disputa de derecho mercantil está constitucionalizada está directamente ligada con la prohibición de omitir la presentación de todos aquellos argumentos constitucionalmente relevantes.

f. La dogmática de los márgenes de acción, y en especial la dogmática de los márgenes de acción estructurales para la ponderación y para la elección de medios, permite conciliar la exigencia de constitucionalización máxima del derecho con la demanda de conservación de autonomía interpretativa y epistemológica del derecho comercial. Esto permite definir aquellos asuntos que son conducidos al margen de acción y que por ello deben ser abordados en el seno de la comunidad jurídica o política, según sea el caso.

g. La corrección constitucional de los argumentos basados en la legislación mercantil se encuentra ligada (i) a la aceptación incondicional del deber de sujeción a la Constitución y (ii) al respeto constante del sistema de precedentes constitucionale ${ }^{58}$. Tal sujeción y tal respeto pueden ser comprobados a medida que se diseña una más completa y elaborada dogmática de los márgenes de acción.

Finalmente, debe advertirse que la constitucionalización del ordenamiento no es, en manera alguna, una cuestión propia del derecho colombiano dado que tal cuestión también ha experimentado un examen especial en otros lugares del mundo. En este sentido, el problema de la constitucionalización del derecho en general, y del derecho comercial en especial, es un problema jurídico de la teoría del derecho.

\footnotetext{
${ }^{58}$ Acerca de la construcción de un sistema de precedentes puede consultarse, entre otros, Diego Eduardo López Medina, El derecho de los Jueces, Ed. Legis 2002. Así mismo, Carlos Bernal Pulido, La Fuerza Vinculante de la Jurisprudencia en el Orden Jurídico Colombiano, Anuario Jurídico, Centro de Investigaciones Socio Jurídicas de la Facultad de derecho y Ciencias Sociales de la Universidad ICESI, 2003, Pág. 13 y ss.
} 